\title{
Correction to: A volumetric positioning error compensation method for five-axis machine tools
}

\author{
Jie Li ${ }^{1} \cdot$ Bin Mei ${ }^{2} \cdot$ Chaolin Shuai $^{1} \cdot$ Xin-jun Liu ${ }^{2} \cdot$ Dawei Liu $^{1}$
}

Published online: 17 June 2019

(C) Springer-Verlag London Ltd., part of Springer Nature 2019

Correction to: The International Journal of Advanced Manufacturing Technology https://doi.org/10.1007/s00170-019-03745-8

The original version of this article contained a mistake.

Due to technical problems at the typesetter, author corrections were not carried out correctly.

The original article has been corrected.

Publisher's note Springer Nature remains neutral with regard to jurisdictional claims in published maps and institutional affiliations.

The online version of the original article can be found at https://doi.org/ 10.1007/s00170-019-03745-8

$\mathrm{Jie} \mathrm{Li}$

15810158892@163.com

1 Chengdu Aircraft Industrial (Group) Co., Ltd., Chengdu 610092, People's Republic of China

2 State Key Laboratory of Tribology and Institute of Manufacturing Engineering, Department of Mechanical Engineering, Tsinghua University, Beijing 100084, People's Republic of China 